\title{
What are the effects of even-aged and uneven-aged forest management on boreal forest biodiversity in Fennoscandia and European Russia? A systematic review protocol
}

Sini Savilaakso 1,3*0, Matti Häkkilä2 ${ }^{2}$ Anna Johansson ${ }^{1}$, Anne Uusitalo ${ }^{4}$, Terhi Sandgren ${ }^{5}$, Mikko Mönkkönen² and Pasi Puttonen ${ }^{3}$

\begin{abstract}
Background: Biodiversity is vital for human well-being, but is threatened by human actions world-wide. In the boreal zone, harvesting and management of forests on an industrial scale is the most important factor driving habitat change and degradation. Over time different forest management regimes have been implemented but their impact on biodiversity at different spatial and temporal scales has not been systematically reviewed although non-systematic reviews on the topic exist. The aim of this article is to describe a protocol for a systematic review to synthesise and compare the impacts of two different forest management systems on biodiversity at different spatial and temporal scales. The topic for the systematic review arose from the discussions with the Finnish forestry sector and was further defined in a stakeholder workshop. Research questions addressed by the systematic review protocol are: (1) What are the stand-level effects of even-aged and uneven-aged forest management on boreal forest biodiversity in Fennoscandia and European Russia? (2) What is the effect of these same forest management systems on biodiversity at landscape level?

Methods: Animal, plant, and fungal diversity is addressed. Bibliographic databases and organizational websites will be searched, and internet search engines will be utilized to find relevant literature. The searches will be conducted in English, Finnish, Swedish, and Russian. Articles will be screened regarding the inclusion and exclusion criteria at title, abstract, and full-text stage. The validity of included studies will be evaluated against appraisal criteria and studies categorized based on their risk of bias. A narrative synthesis will be conducted to describe the findings. If enough quantitative data can be retrieved from the studies, a meta-analysis will be conducted.
\end{abstract}

Keywords: Clear-cut, Continuous cover forestry, Landscape, Species diversity, Species richness

*Correspondence: sini.savilaakso@metsateho.fi

${ }^{1}$ Metsäteho Oy, Vernissakatu 1, 01300 Vantaa, Finland

Full list of author information is available at the end of the article 


\section{Background}

In the boreal zone, harvesting and management of forests on an industrial scale is the most important factor driving habitat change and degradation [1]. In addition to regular harvesting, removal of stumps and harvesting residues for energy wood has increased in recent decades because of the current climate policies in Europe [2] but also in North America [3]. Stump removal increases the degree of disturbance by decreasing the amount of dead wood dramatically $[4,5]$ and may therefore lead to stronger responses of the dead-wood dependent species. There are lots of studies on the impacts of forest harvesting on different species groups in Fennoscandia, and long-term monitoring shows declines of biological communities, for example in many forest bird populations $[6$, 7]. Also, species assemblages may not be maintained in protected areas if they are embedded in heavily managed landscape $[8,9]$. Under these circumstances the management of productive forests is a key aspect for maintaining biodiversity.

A common forest management regime in the whole boreal zone has long been even-aged management (Table 1) [10]. In Finland, for example, even-aged management was the primary management regime in forestry dictated by law for more than 60 years, until the year 2014, when uneven-aged management regime was enabled again [11]. As boreal forests in their natural state are usually heterogenic with trees and stands of different species, ages and size, even-aged management simplifies the forest structure which is noticed to have negative impacts on biodiversity [12].

To slow down the decline of forest species diversity alternative management regimes have been taken into practice. Retention forestry [13] is usually similar to even-aged management, but some old trees, dead or living, or small stands of trees are retained in harvest to create structural diversity [14, 15]. In uneven-aged management, i.e. continuous-cover forestry, harvested patches are usually smaller than in even-aged management, mature trees or tree groups are selected for harvesting, and younger trees are left to grow [10]. Uneven-aged forest management aims for more heterogeneous stand structures, assumed to be less damaging to forest biodiversity than clear-cuts [16].

Even though even-aged management is still the most common harvesting method in Finland, Sweden and Norway, the public interest towards uneven-aged forest management has increased in the last decades [17-21]. In European Russia, most final feellings are clear-cuts and continuous cover forestry with selective logging method is more widely used only in western parts of the country in Murmansk and Leningrad regions [22].

Despite the rising public interest, the adoption of uneven-aged forest management in Finland, Sweden and Norway has been relatively modest. There is a strong, ongoing debate on economic profitability of uneven-aged management, with studies showing that at least in some forest types uneven-aged management would be more profitable than even-aged management [23, 24]. Similarly, recent scientific studies suggest that uneven-aged management provides higher values for some biodiversity aspects but even-aged management for others [10, 25]. Therefore, it is not surprising that there is no strong consensus between stakeholders on the impacts of these two forest management regimes on biodiversity [26].

The topic for the systematic review arose from the discussions with the Finnish forest industry on their evidence needs related to sustainability issues. In

Table 1 Definitions of different forest management regimes. Also, common synonyms for the main term are given

\begin{tabular}{|c|c|c|}
\hline Forest management regime & Synonyms & Definition \\
\hline Even-aged forest management & clear-cutting, clear-felling & $\begin{array}{l}\text { Management method that produces relatively homog- } \\
\text { enous forest structures. Forest rotation is controlled } \\
\text { by planting, thinning and regeneration felling. During } \\
\text { the regeneration felling all the trees in the area are } \\
\text { removed. }\end{array}$ \\
\hline Retention forestry & & $\begin{array}{l}\text { Management method almost similar to even-aged } \\
\text { management, but some individual trees (dead or } \\
\text { alive) or tree groups are left standing during the } \\
\text { regeneration fell. This aims to enhance the structural } \\
\text { diversity of the harvesting area. }\end{array}$ \\
\hline Uneven-aged forest management & $\begin{array}{l}\text { continuous cover forestry, selective cutting/felling, } \\
\text { selection cutting/felling, partial cutting/felling, gap } \\
\text { cutting/felling, patch cutting/felling }\end{array}$ & $\begin{array}{l}\text { Management method where only some of the trees are } \\
\text { removed in one harvest. Forest regenerates through } \\
\text { the trees left standing and no plantation is needed. } \\
\text { The forest structure stays heterogenous and this can } \\
\text { be achieved by cutting single trees (selective felling) } \\
\text { or tree groups (gap felling). }\end{array}$ \\
\hline
\end{tabular}


Finland $91 \%$ of forests are in commercial timber production [27] and hence, forest industry has large influence on forest biodiversity. Specifically, three forestry companies (Metsä Group, Stora Enso Oyj, and UPMKymmene Oyj), industry representative group Finnish Forest Industries, and the state-owned enterprise Metsähallitus, which is responsible for the management of one-third of Finland's surface area, participated in the discussions that lead to the broad definition of the topic. The topic was further defined in a stakeholder workshop that was held 23 August 2018. Purposive selection based on known contacts, snowballing, and internet search were used to compile a list of stakeholders following recommendations by Haddaway et al. [28]. An open invitation to participate in the workshop was published on the website of the Evidence-Based Forestry in Finland initiative 24 July 2018 and sent by email to 35 stakeholder organisations (Additional file 1) with a notice that it can be further shared with interested individuals and organisations. A reminder email was sent 2 weeks later to those individuals and organisations that had not responded.

In the end, 13 individuals from 12 stakeholder organisations participated in the workshop (Additional file 1). At the workshop, the topic, research questions, initial theory of change, PECO-based search terms, and factors creating heterogeneity were presented and discussed. Based on the discussion with the participants the topic was narrowed to the two research questions that are presented in this protocol. The participants also suggested sources of grey literature and potential sources for unpublished data. Comments and suggestions of the participants related to other elements discussed have been integrated into the protocol.

\section{Objective of the review}

The objective of the review is to systematically review and synthesise results of the studies on the impacts of even-aged and uneven-aged forest management on biodiversity, specifically species of different taxa, at different spatial and time scales. Figure 1 shows a simple theory of change of the impacts of forest harvesting on biodiversity. The review will focus on Fennoscandia (Finland, Sweden and Norway) and European Russia. The geographical scope of the review was discussed at the stakeholder workshop and is based on the similarity of the forests, including tree species, and their management.

The review has two key research questions:

1. What are the stand-level effects of even-aged and uneven-aged forest management on boreal forest biodiversity in Fennoscandia and European Russia?

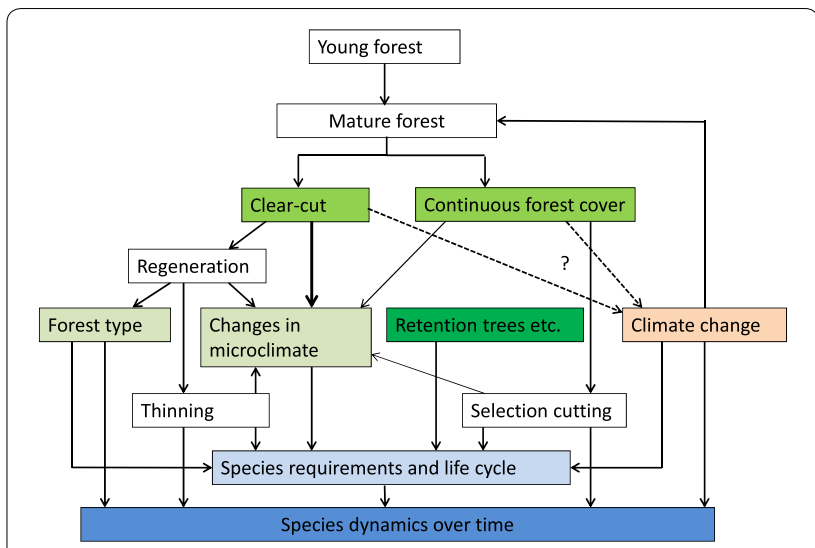

Fig. 1 Simplified depiction of impact pathways influencing species assemblages over time. Clear-cut is a typical management practice for even-aged forest management whereas uneven-aged forest management retains continuous forest cover. In practice, the dichotomy between even-aged and uneven-aged forest management regimes is less distinct than depicted here due to effect modifiers such as the number of retention trees, gap size, and felling style

2. What is the effect of forest management on boreal forest biodiversity in Fennoscandia and European Russia at landscape level?

The impacts of even-aged and uneven-aged forest management regimes will be compared to each other as well as to forest areas where no intervention has taken place to give a full picture of the impacts. The first question focuses on the impact of different forest management regimes on alpha diversity whereas the second question focuses on gamma diversity. Most of the biodiversity studies are standlevel studies focused on species richness and other alpha diversity measures, which commonly decrease in response to harvesting. However, it is important to know whether the stand-level habitat loss means an overall loss of biodiversity at a larger scale or whether biodiversity is maintained despite a temporary loss of a habitat in one or more places in the landscape that is formed by the different forest stands. The question components are outlined in Table 2.

\section{Methods}

This protocol follows the guidelines of Collaboration for Environmental Evidence and complies with the ROSES reporting standards. The ROSES form is included as an Additional file 2.

\section{Searching for articles Search string}

A list of search terms relating to the PECO components was proposed at the stakeholder meeting and validated by the participants (Table 3 ). 
Table 2 Components of the review questions

\begin{tabular}{|c|c|c|c|}
\hline Subject & Exposure & Comparator & Outcomes \\
\hline Boreal forest & $\begin{array}{l}\text { Even-aged or uneven-aged forest manage- } \\
\text { ment }\end{array}$ & No intervention; Other forest management & $\begin{array}{l}\text { Biodiversity indicators, such as species } \\
\text { diversity, richness, individual abundance }\end{array}$ \\
\hline
\end{tabular}

Table 3 Search terms proposed at the stakeholder meeting

\begin{tabular}{|c|c|c|c|c|}
\hline $\begin{array}{l}\text { Forest } \\
\text { type } \\
\text { (subject) }\end{array}$ & Taxa of interest & Intervention & Comparator & Outcomes \\
\hline $\begin{array}{l}\text { Boreal, } \\
\text { spruce, } \\
\text { pine }\end{array}$ & $\begin{array}{l}\text { Vegetation, plant, fungi, bird, } \\
\text { polypore, insect, beetle, } \\
\text { mammal, arthropod }\end{array}$ & $\begin{array}{l}\text { Clear-cut, clearcut, clear- } \\
\text { fell, clearfell, even-aged, } \\
\text { uneven-aged, continuous } \\
\text { cover, regeneration fell, } \\
\text { management }\end{array}$ & $\begin{array}{l}\text { Protected area, national park, } \\
\text { nature reserve, natural } \\
\text { forest, primary forest, selec- } \\
\text { tive harvest, retention cut, } \\
\text { partial harvest, old-growth, } \\
\text { mature }\end{array}$ & $\begin{array}{l}\text { Diversity, richness, assemblage, abun- } \\
\text { dance }\end{array}$ \\
\hline
\end{tabular}

Based on the five categories, a search string was formulated using Boolean operators 'OR', 'AND' and 'NEAR'. The performance of the search string was tested using a test list of 20 articles collected from previous reviews and from experts (Additional file 3). The testing was conducted primarily in the Web of Science (Core Collection) but also included testing in Scopus and CAB Abstracts (Additional file 4). After scoping and taking reviewer suggestions into account, the search string was modified into its current form. The final search string in English is:

\#1 TS $=(($ Boreal NEAR/5 (forest* OR zone OR tree* $))$ OR taiga OR spruce* OR picea OR pine* OR pinus OR birch* OR aspen* OR populus).

\#2 TS = (Finland OR Finnish OR Swed* OR Norw* OR Russia* OR Fennoscan* OR Scandin* OR "north* europ*" OR "nord* countr*") and TS $=$ (forest* OR tree*).

\#3 TS = (clear-cut* OR clearcut* OR clearfell ${ }^{*}$ OR clearfell* OR "clear fell*" OR even-aged OR uneven-aged).

\#4 TS = (forest" NEAR/5("continu* cover" OR "natural* regenerat*" OR multiage $^{*}$ OR alternativ* OR "common" sens" " OR unmanaged OR managed OR sustainabl*)).

\#5 TS = (silvicult* NEAR/5("continu* cover"” OR "natural* regenerat*" OR multiage* OR alternativ* OR "common" sens" ${ }^{*}$ " OR unmanaged OR managed OR sustainabl*)).

\#6 TS = (Regenerat* NEAR/5 (cut* OR fell* OR harvest* OR $\left.\log ^{*}\right)$ ) OR TS $=($ select* NEAR/5 (cut* OR fell* OR harvest* OR $\left.\log ^{*}\right)$ ) OR TS $=($ partial* NEAR/5 (cut* OR fell* OR harvest* OR $\left.\log ^{*}\right)$ ) OR TS $=($ alternat* NEAR/5 (cut* OR fell* OR harvest* OR log*)) OR $\mathrm{TS}=\left(\right.$ retent $^{*}$ NEAR/5 (cut* OR fell* OR harvest* OR

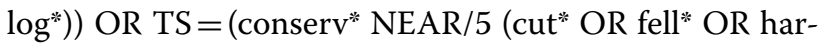
vest* OR $\left.\left.\log ^{*}\right)\right)$ OR TS $=\left(\right.$ gap $^{*}$ NEAR/5 $\left(\right.$ cut* $^{*}$ OR fell* OR harvest* OR $\left.\left.\log ^{*}\right)\right)$ OR TS $=($ patch* NEAR/5 (cut* OR fell* OR harvest* OR $\left.\left.\log ^{*}\right)\right)$ OR TS $=($ dispers* NEAR/5 (cut* OR fell* OR harvest* OR $\left.\log ^{*}\right)$ ).

\#7 TS = (biodiversi* OR fauna OR flora OR fungi OR eukaryot* OR vertebrat* OR invertebrat* OR animal* OR plant* OR arthropod* OR lichen* OR insect* OR bird* OR mammal* OR vegetat* OR bryophyte* OR amphibian* OR reptile*).

\#8 TS = (species NEAR/5 (divers* OR rich* OR assemb* OR abund*)).

\#9 \#2 OR \# 1 .

\#10 \#6 OR \#5 OR \#4 OR \#3.

\#11 \#8 OR \#7.

\#12 \#11 AND \#10 AND \#9.

The search string will be translated to other search languages. It will be simplified by reducing the number of search terms to search organizational websites and to conduct internet searches where the search interface often has more limited capacity regarding search strings. Boolean operators will be used to combine main search terms whenever the search engine allows it. The used search strings will be recorded and published as additional information in the review report.

A search alert will be set in bibliographic databases to screen articles that are published before the data synthesis commences. The number of articles retrieved through the search alerts will be reported in the review report.

\section{Languages}

The systematic review will include studies published in English, Finnish, Swedish, and Russian. The selection of languages is based on the geographical scope of the systematic review and limited by the language skills of the review team. Organisational websites will be searched in the primary language the website is published except the websites in Norwegian, which will be searched in English. 
In addition, if the publications section includes studies published in other of the review languages (e.g. main website language is Swedish but there are also unique publications in English), the search will be conducted in those languages as well.

\section{Bibliographic searches}

The following bibliographic searches will be conducted:

- CAB Abstracts (https://www.cabi.org/); Keyword search from 1973 onwards.

- Directory of Open Access Repositories (https://doaj. org/); 'Search all' field will be used with not further limitations.

- Digital Dissertations Library of Russian State Library (http://diss.rsl.ru/).

- Doria (https://www.doria.fi/).

- Helka-University of Helsinki Catalogue (https:// helka.finna.fi/); All fields will be searched with no further limitations.

- Jultika-University of Oulu repository; All fields will be searched with no further limitations.

- JYX-Publication archive of the University of Jyväskylä.

- Russian Science Citation Index on the Web of Science (https://clarivate.com/); Topic search, access from 2005 onwards.

- Russian Scientific Electronic Library (https://elibrary. $\mathrm{ru} /)$.

- Scopus (https://www.scopus.com/home.uri); Title, abstract, and keyword search.

- Swedish University Dissertations (http://www.avhan dlingar.se/).

- UTUPub-University of Turku repository.

- Web of Science Core collection (https://clarivate. $\mathrm{com} /$ ); Topic search covering all years within Science Citation Index Expanded (1945-present), Social Sciences Citation Index (1956-present), Arts \& Humanities Citation Index (1975-present), Conference Proceedings Citation Index-Science (1990-present), Conference Proceedings Citation Index-Social Science \& Humanities (1990-present), Emerging Sources Citation Index (2015-present).

\section{Search engines}

- Google Scholar (https://scholar.google.com/); Title search will be conducted with the function 'at least one of the words.'

- Google (https://www.google.com/).
The internet searches will be conducted in 'private' mode to prevent the influence of previous browsing history and location on search results. The results will be organised by relevance. After the first 50 hits, results will be checked until relevant articles are no longer retrieved as advised in Livoreil et al. [29]. The date and number of hits received and searched will be recorded and included in the review report.

\section{Organisational websites}

The websites of the specialist organisations listed below will be searched. The Russian websites will be searched manually due to the low performance of the "search" function to find relevant hits based on scoping of the organisational websites. If the organisation is publishing a journal, the site of the journal will also be searched if the journal is not already included in some of the bibliographic databases searched.

- All-Russian Research Institute of Silviculture and Mechanization of Forestry (http://www.vniilm.ru)

- Bellona Foundation (http://bellona.ru/)

- BiodivERsA-the network programming and funding research on biodiversity and ecosystem services across European countries and territories (https:// www.biodiversa.org/)

- Biodiversity Conservation (Russia) (http://www.biodi versity.ru/)

- Centre for Economic Development, Transport and the Environment (Finland) (https://www.ely-kesku s.fi/)

- Community Research and Development Information Service (https://cordis.europa.eu/home_en.html)

- Confederation of European Forest Owners (http:// www.cepf-eu.org/)

- Convention on Biological Diversity (https://www. cbd.int/)

- European Forest Insititute (https://www.efi.int/)

- Federal Forestry Agency (Russia) (http://rosleshoz. gov.ru/)

- Federal State Budget Education Institution of Higher Education Voronezh State University of Forestry and Technologies named after G.F. Morozov (http://vgltu $. \mathrm{ru} /$ )

- Finnish Association for Nature Conservation (https ://www.sll.fi/)

- Finnish Environment Insititute (http://www.syke.fi/)

- Finnish Forest Association (https://smy.fi/)

- Finnish Forest Centre (https://www.metsakeskus.fi/)

- Finnish Forest Foundation (http://www.metsasaati o.fi/) 
- Finnish Nature League-Luonto-Liitto (http://www. luontoliitto.fi/)

- Finnish Society of Forest Science (http://www.metsa tieteellinenseura.fi/)

- Food and Agriculture Organization of the United Nations (http://www.fao.org/home/en/)

- Forestry Research Institute of Sweden (https://www. skogforsk.se/)

- Foundation for Strategic Environmental Research (Sweden) (https://www.mistra.org/)

- Greenpeace Finland (http://www.greenpeace.org/ finland/fi/)

- Greenpeace International (https://www.greenpeace .org/international/)

- Greenpeace Russia (https://www.greenpeace.org/ russia/ru/)

- Greenpeace Sweden (http://www.greenpeace.org/ sweden/se/)

- International Boreal Forest Research Association (http://ibfra.org/).

- International Union for Conservation of Nature (https://www.iucn.org/)

- International Union of Forest Research Organizations (https://www.iufro.org/)

- IVL Swedish Environmental Research Institute (https ://www.ivl.se/).

- Metsähallitus (http://www.metsa.fi/)

- Metsäteho (http://www.metsateho.fi/)

- Ministry of Agriculture and Food (Norway) (https:// www.regjeringen.no/no/dep/lmd/id627/)

- Ministry of Agriculture and Forestry (Finland) (https ://mmm.fi)

- Ministry of the Environment (Finland) (http://www. ym.fi)

- Ministry of the Environment and energy (Sweden) (https://www.regeringen.se/sveriges-regering/miljooch-energidepartementet/)

- Ministry of Natural Resources and Environment of the Russian Federation (http://www.mnr.gov.ru/)

- Natural Resources Institute Finland (https://www. luke.fi/)

- NOLTFOX-Northern European Database for LongTerm Forest Experiments (http://noltfox.metla.fi/)

- Northern Research Institute of Forestry (http://www. sevniilh-arh.ru)

- Norwegian Forest Research Institute (http://www. skogforsk.no/)

- Norwegian Institute of Bioeconomy Research (NIBIO) (https://www.nibio.no/)

- Norwegian Institute for Nature Research (https:// www.nina.no/)
- Norwegian Society for the Conservation of Nature, Friends of the Earth Norway (https://naturvernf orbundet.no/)

- Norwegian State Forest and Land Corporation (https ://www.statskog.no/)

- Regional Public Nature Conservation Organization of Karelia (Russia) (http://spok-karelia.ru/)

- Research institute of Sweden (https://www.ri.se/)

- Royal Swedish Academy of Agriculture and Forestry (http://www.ksla.se/)

- Russian Academy of Sciences (http://www.ras.ru/)

- Centre for Forest Ecology and Productivity (http:// cepl.rssi.ru/)

- Forest Research Institute of Karelian Research Centre (http://forestry.krc.karelia.ru/)

- Ural Branch, Institute of Biology of Komi Scientific Centre, Department of Forest Science (https ://ib.komisc.ru/rus/)

- Russian Center for the Protection of Forests (http:// rcfh.ru/)

- Russian Institute of Continuous Education in Forestry (http://vipklh.ru/)

- Saint-Petersburg Forestry Research Institute (http:// spb-niilh.ru/)

- Saint-Petersburg State Forest Technical University (http://spbftu.ru/)

- SNS Nordic Forest Research (http://nordicforestres earch.org/)

- Skydda Skogen (http://skyddaskogen.se/sv/)

- Stockholm Environment Institute (https://www.sei. org/)

- Swedish environmental protection agency (http:// www.naturvardsverket.se/)

- Swedish Forest Agency (https://www.skogsstyrelsen. se/)

- Swedish Forest Society (https://www.skogssallskapet .se/)

- Swedish Forestry Association (https://www.skoge n.se/)

- Swedish Research Council Formas (http://www. formas.se/)

- Swedish Society for Nature Conservation (https:// www.naturskyddsforeningen.se/)

- Tapio (http://tapio.fi/)

- United Nations Forum on Forests (http://www. un.org/esa/forests/)

- WWF Finland (https://wwf.fi/)

- WWF Global (http://wwf.panda.org/)

- WWF Russia (https://wwf.ru/)

- WWF Sweden (http://www.wwf.se/) 


\section{Supplementary searches}

Citation chasing will be undertaken to supplement the search. A call for unpublished data will be published on the website of the Evidence-Based Forestry in Finland project (http://npmetsa.fi/en/frontpage/) and sent directly to stakeholder organisations that may have unpublished data on the topic. Also, data will be asked from individuals suggested at the stakeholder workshop.

\section{Search record database}

The search results will be exported into separate files using a reference management software. If the document cannot be exported into a reference management software, a record will be created manually into a separate file. Once all the searches have been conducted, the reference files will be merged, and duplicates will be removed before commencing article screening.

\section{Article screening and study eligibility criteria Screening process}

Articles will be screened by three people at the title, abstract, and full text level. At the title stage, a random set of 100 articles will be independently screened by all three screeners. If their screening decisions are in agreement, i.e. they would include/exclude the same articles, rest of the articles will be divided among the screeners. If their screening decisions differ, discrepancies in inclusion decisions are discussed to facilitate consistency before another 100 articles will be independently screened. The process will be repeated until 95 to $100 \%$ screener agreement is achieved. The process will be repeated at the abstract stage with a random set of 50 articles. If a screener is unsure whether to include an article, it will be moved to the next stage. Articles at the full text stage will be screened by all three screeners except for studies in Russian that will be screened by only one person at all stages. To check that inclusion criteria is used consistently, the Russian speaker will talk the other screeners through the decision process on a random set of 20 articles at each of the screening stages.

The review may include articles published by the authors of the review. Their inclusion in the review at the screening and critical appraisal stage will be jointly determined by the other authors in accordance with the eligibility and appraisal criteria.

\section{Eligibility criteria}

The eligibility criteria are based on the PECO components, study design and geographical location of the studies (Tables 4 and 5). Only studies conducted in Finland, Sweden, Norway and European Russia will be included.

At each stage of the screening a separate file will be created of the excluded articles. At the full text stage, a
Table 4 The eligibility criteria for article screening for the study question 1

\begin{tabular}{ll}
\hline Question elements & Eligibility criteria \\
\hline Population & Included: Boreal forests in Fennoscandia and \\
European Russia & Included: Even-aged and uneven-aged manage- \\
ment & Included: Different forest management regimes, \\
including retention forestry, and areas with no \\
intervention, including protected forest areas, \\
national parks \\
Excluded: Non-forest lands, e.g. agricultural areas, \\
parks in urban areas, wooded fields, e.g. christ- \\
mas tree plantations \\
Included: Species richness, species diversity, \\
abundance \\
Excluded: Community composition indices \\
Included: Before-after (BA), control-intervention \\
studies (CI), and studies combining both (BACI). \\
Also, randomized controlled trials (RCT).
\end{tabular}

Table 5 The eligibility criteria for article screening for the study question 2

\begin{tabular}{|c|c|}
\hline Question elements & Eligibility criteria \\
\hline Population & $\begin{array}{l}\text { Included: Boreal forests in Fennoscandia and } \\
\text { European Russia }\end{array}$ \\
\hline Exposure & $\begin{array}{l}\text { Included: Even-aged and uneven-aged manage- } \\
\text { ment }\end{array}$ \\
\hline Comparators & $\begin{array}{l}\text { Included: Forest areas with no intervention, includ- } \\
\text { ing, protected forest areas, mature production } \\
\text { forest, national parks }\end{array}$ \\
\hline Outcomes & Included: Species richness and abundance \\
\hline Study design & $\begin{array}{l}\text { Included: Before-after (BA), control-intervention } \\
\text { studies }(\mathrm{Cl}) \text {, and studies combining both (BACI). } \\
\text { Also, randomized controlled trials (RCT). }\end{array}$ \\
\hline
\end{tabular}

reason for exclusion will be recorded, and a list of the excluded articles with the reason for rejection will be included as additional information in the review report.

If there are multiple articles from one study site (i.e. linked articles), they will be appraised as a group to avoid inclusion of duplicate data following Frampton et al. [30]. True duplicate studies will be removed, and the rest will be screened as a single unit to consider all available data pertinent to the study when making eligibility decisions.

\section{Study validity assessment}

All studies included in the full text stage will be critically appraised and categorized as 'low', 'medium' or 'high' risk of bias. The assessment is based on the following factors (Table 6): 
Table 6 Critical appraisal criteria to assess studies in the full text stage

\begin{tabular}{|c|c|c|c|}
\hline Factor & Low & Medium & High \\
\hline Study design & $\begin{array}{l}\text { Experimental studies (includes also } \\
\text { quasi-experimental studies) }\end{array}$ & Observational studies & Case studies \\
\hline Sampling & $\begin{array}{l}\text { Large sample size } \\
\text { Sampling method suitable for the } \\
\text { population of interest } \\
\text { Properly conducted randomisation of } \\
\text { study areas } \\
\text { Random sampling of study subjects } \\
\text { Control and intervention areas } \\
\text { matched }\end{array}$ & $\begin{array}{l}\text { Small to medium sample size } \\
\text { Sampling method suitable for the } \\
\text { population of interest } \\
\text { Control and intervention areas com- } \\
\text { parable based on their ecological } \\
\text { characteristics }\end{array}$ & $\begin{array}{l}\text { Sampling method not suitable for } \\
\text { collecting data on the population } \\
\text { of interest }\end{array}$ \\
\hline $\begin{array}{l}\text { Accounting for heterogene- } \\
\text { ity and potential effect } \\
\text { modifiers }\end{array}$ & $\begin{array}{l}\text { Effect modifiers identified, and data } \\
\text { collected on them }\end{array}$ & $\begin{array}{l}\text { Effect modifiers identified and consid- } \\
\text { ered in relation to the results }\end{array}$ & $\begin{array}{l}\text { Effect modifiers not identified or } \\
\text { considered }\end{array}$ \\
\hline Data analysis methods & Methods appropriate & Methods appropriate & Methods not appropriate \\
\hline
\end{tabular}

- Study design.

- Sampling.

- Accounting for potential effect modifiers and heterogeneity.

- Data analysis methods.

Studies that fulfil any one of the criteria in the category 'high' will be excluded. Also, studies with insufficient methodological description will be excluded if sufficient clarifying details are not received by contacting the author of the study. All the studies will be assessed by two persons, and any inconsistencies or uncertainties discussed with other research group members.

\section{Data coding and extraction strategy}

Data from included studies will be extracted and recorded in an Excel spreadsheet (Additional file 5) and will be made available as supplementary information of the systematic review. Data will include study meta-data (study characteristics) and data on outcomes, e.g. sample size, mean, standard deviation (SD), and standard error (SE) (see Additional file 5 for a full list). Data on test statistics that can be converted into effect size metrics will be collected in case data on outcome mean, SD or SE is not available. Also, data on effect modifiers and potential sources of heterogeneity will be extracted to enable statistical exploration of the relationship between outcomes and sources of heterogeneity at the data analysis stage. All the extracted data will be published as supplementary information of the review. If an article contains independent results from more than one study, these will be treated as separate studies in data extraction. Authors of the studies will be contacted to retrieve any missing information or data.

Data will be extracted by more than one person. Hence, a set of five studies will be coded together to ensure consistency. If there are conflicting decisions on what data to extract, the decisions will be discussed among the group. Also, any uncertainties regarding data extraction will be discussed among the group. Data from the studies in Russian will be extracted by one person only. The person will discuss any uncertain decisions with the research group members.

\section{Potential effect modifiers and reasons for heterogeneity}

To understand possible variation in the effects of studies better, possible effect modifiers will be extracted from the studies. As the studies included in this systematic review may have been completed in a relatively large area, there are several factors that may cause heterogeneity among studies, such as climatic conditions and geographic location of the study site. Also, temporal variation is expected. The year a study was conducted may influence the results as forest management has changed over the years. Also, time passed since intervention was started may cause variation depending on the timing and nature of harvests as well as natural succession of vegetation after harvests. Energy wood harvesting, i.e. removing stumps and branches beyond regular harvesting may have various impacts on biodiversity mainly by reducing the amount of dead wood [2, 31]. Habitat connectivity can be an important factor in the dispersal of species across the landscape, and there are several estimates that can be used to quantify connectivity. In case the used connectivity estimates differ between the included studies, we will instead use categories low, medium or high in the data analysis.

Below is a non-comprehensive list of potential effect modifiers and sources of heterogeneity. Additional effect modifiers and sources of heterogeneity may be identified from the studies included in the review. The list was 
compiled based on the authors' experience and consultation at the stakeholder meeting.

- Geographic location

- Climatic conditions

- The year(s) the study was conducted

- Time since the intervention started

- The length of the study

- Size and extent of sampling area

- Forest type and soil type

- Humidity (drained vs. non-drained)

- Connectivity of the study site(s)

- Differences in management type (for example, single tree selection and small patch selection felling are both considered as continuous cover forestry)

- Certification

- Owner of the study site(s) (private, company, state)

- Harvesting of energy wood (stumps, branches)

\section{Data synthesis and presentation}

A narrative synthesis of data from all the included studies will be produced. The narrative synthesis will describe the evidence-base with tables and figures, including description of interventions and comparators, study locations and designs, length of the studies, and studied taxa. It will also describe the effects of the interventions on biodiversity outcomes.

If enough quantitative data can be extracted from the included studies, a meta-analysis will be conducted to assess the effects of forest management on biodiversity outcomes at stand-level. If data allows, sub-group analyses on different taxa will be undertaken. Furthermore, heterogeneity in the results will be explored using metaregression if there is enough data to conduct the analysis. In case there are several outcomes from the same experimental setup, their treatment will be considered prior to the statistical analyses to avoid the risk of false-positive results. Also, only data from comparable settings will be included in the same analysis. For example, before-after data from pforest that has been previously harvested will not be compared with data from control-intervention design that compares (unharvested) national park with production forest. If enough data for meta-analysis cannot be extracted, other analytical methods will be considered alongside narrative synthesis.

To assess landscape level diversity (gamma diversity) a framework developed by Chao et al. [32] will be used. It uses effective number of species (Hill numbers) incorporating relative abundance, which makes it suitable for landscape level comparisons of species assemblages. Hill numbers $\left({ }^{9} \mathrm{D}\right)$ quantify diversity in units of equivalent numbers of equally abundant species by increasingly weighting abundance with the order of diversity q. If there is missing or incomplete information in the article, and that information cannot be retrieved by contacting the authors, the study will be excluded from the analyses.

When the systematic review is conducted steps are taken to minimise bias in the results, for example by searching extensively both peer-reviewed and grey literature and by excluding articles that have high risk of bias. To test the effect of the validity assessment (i.e. exclusion of articles) and the robustness of the studied outcomes, a sensitivity analysis will be conducted. This will be done by conducting analyses including and excluding studies with high risk of bias. Not all sources of bias can be excluded, such as publication bias which stems from the practice that studies showing statistically significant effect are more likely to be published than those that do not. Therefore, the presence of publication bias will be evaluated visually by producing funnel plots. If publication bias is detected visually, 'trim and fill' method will be used to adjust the results for publication bias if enough data is available to do this.

\section{Additional files}

Additional file 1. Stakeholder organisations (A list of stakeholder organisations invited to the stakeholder workshop).

Additional file 2. ROSES form.

Additional file 3. Test list (List of articles to test the performance of the search).

Additional file 4. The performance of the search string.

Additional file 5. Data extraction spreadsheet.

\section{Authors' contributions}

SS, MH, AJ wrote the first draft. AU and TS built and tested the final search string. MM and PP contributed to the subsequent versions of the manuscript. All authors read and approved the final manuscript.

\section{Author details}

${ }^{1}$ Metsäteho Oy, Vernissakatu 1, 01300 Vantaa, Finland. ${ }^{2}$ Department of Biological and Environmental Science, University of Jyväskylä, Survontie 9 C, Ylistönrinne, 40014 Jyväskylä, Finland. ${ }^{3}$ Department of Forest Sciences, University of Helsinki, Latokartanonkaari 7, 00014 Helsinki, Finland. ${ }^{4}$ Helsinki University Library, University of Helsinki, Viikki Campus, Viikinkaari 11 A, 00014 Helsinki, Finland. ${ }^{5}$ Helsinki University Library, University of Helsinki, Fabianinkatu 30, 00014 Helsinki, Finland.

\section{Acknowledgements}

The authors thank all the workshop participants for their contributions to the protocol and for the interesting discussions during the workshop. We thank Andrew Pullin and the reviewers for their valuable suggestions and comments that helped to improve the manuscript.

\section{Competing interests}

The authors declare that they have no competing interests.

Availability of data and materials

Not applicable. 


\section{Consent for publication \\ Not applicable.}

\section{Ethics approval and consent to participate}

Not applicable.

\section{Funding}

This protocol and the forthcoming review are funded by the Finnish Forest Foundation, Grant Number 2018070301. The Foundation has not participated in the development of this protocol in any way.

\section{Publisher's Note}

Springer Nature remains neutral with regard to jurisdictional claims in published maps and institutional affiliations.

Received: 25 October 2018 Accepted: 15 March 2019

Published online: 02 April 2019

\section{References}

1. Hanski I. The shrinking world: ecological consequences of habitat loss. Oldendorf: International Ecological Institute; 2005.

2. Toivanen T, Markkanen A, Kotiaho JS, Halme P. The effect of forest fuel harvesting on the fungal diversity of clear-cuts. Biomass Bioenerg 2012:39:84-93.

3. Sullivan TP, Sullivan DS, Lindgren PMF, Ransome DB, Bull JG, Ristea C. Bioenergy or biodiversity? Woody debris structures and maintenance of red-backed voles on clearcuts. Biomass Bioenerg. 2011;35(10):4390-8.

4. Rudolphi J, Gustafsson L. Effects of forest-fuel harvesting on the amount of deadwood on clear-cuts. Scand J For Res. 2005;20(3):235-42.

5. Eräjää S, Halme P, Kotiaho JS, Markkanen A, Toivanen T. The volume and composition of dead wood on traditional and forest fuel harvested clearcuts. Silva Fenn. Finnish Soc For Sci. 2010;44:203-11.

6. Valkama J, Vepsäläinen $\mathrm{V}$, Lehikoinen $\mathrm{A}$. The third finnish breeding bird atlas. 2011. http://atlas3.lintuatlas.fi/english.

7. Tiainen J, Mikkola-Roos M, Below A, Jukarainen A, Lehikoinen A, Lehtiniemi T, et al. Suomen Lintujen Uhanalaisuus 2015-the red list of finnish bird species. Helsinki: Ministry of the Environment \& Finnish Environment Institute; 2016. p. 49

8. Häkkilä M, Le Tortorec E, Brotons L, Rajasärkkä A, Tornberg R, Mönkkönen M. Degradation in landscape matrix has diverse impacts on diversity in protected areas. PLoS ONE. 2017;12:9.

9. Häkkilä M, Abrego N, Ovaskainen O, Mönkkönen M. Habitat quality is more important than matrix quality for bird communities in protected areas. Ecol Evol. 2018:8(8):4019-30.

10. Chaudhary A, Burivalova Z, Koh LP, Hellweg S. Impact of forest management on species richness: global meta-analysis and economic trade-offs. Sci Rep. 2016;6(1):23954

11. Appelroth E, Heikinheimo O, Kalela E, Laitakari E, Lindfors J, Sarvas R. Julkilausuma. Metsätaloudellinen Aikakausl. 1948:65:315-6.

12. Hanski I. Insect conservation in boreal forests. J Insect Concervation. 2008;12:451-4.

13. Gustafsson L, Baker SC, Bauhus J, Beese WJ, Brodie A, Kouki J, et al. Retention forestry to maintain multifunctional forests: a world perspective. Bioscience. 2012;62(7):633-45.

14. Lindenmayer DB, Laurance WF, Franklin JF. Global decline in large old trees. Science (80-). 2012;338(6112):1305-6.
15. Fedrowitz K, Koricheva J, Baker SC, Lindenmayer DB, Palik B, Rosenvald R, et al. REVIEW: can retention forestry help conserve biodiversity? A metaanalysis. J Appl Ecol. 2014;51(6):1669-79.

16. Falk KJ, Burke DM, Elliott KA, Holmes SB. Effects of single-tree and group selection harvesting on the diversity and abundance of spring forest herbs in deciduous forests in southwestern Ontario. For Ecol Manage. 2008;255(7):2486-94.

17. Yrjölä T. Forest management guidelines and practices in Finland, Sweden and Norway. EFI Internal Report. 2002

18. Oleskog G, Nilson K, Wikberg P. Kontinuitetsskogar och Kontinuitetsskogsbruk-Slutrapport för delproject Skötsel-hyggesfritt skogsbruk. Rapport 22. Skogsstyrelsen;

19. Rolstad J, Gjerde I, Storaunet KO, Rolstad E. Epiphytic lichens in Norwegian coastal spruce forest: historic logging and present forest structure. Ecol Appl. 2001;11(2):421-36.

20. Living Forests. Standard for sustainable management in Norway. 2006. http://www.levendeskog.no/levendeskog/vedlegg/51Levende_Skog_ standard Engelsk.pdf. Accessed 11 Jan 2019.

21. Kunttu P. Avohakkuiden pakkovallan kausi-synkkä jakso suomalaista metsähistoriaa. Elonkehä. 2017:4:16-24.

22. Karjalainen T, Leinonen T, Gerasimov Y, Husso M, Karvinen S. Intensification of forest management and improvement of wood harvesting in Northwest Russia. Final report of the research project. Working papers of the Finnish Forest Research Institute 110. 2009.

23. Kuuluvainen T, Tahvonen O, Aakala T. Even-aged and uneven-aged forest management in Boreal Fennoscandia: a review. Ambio. 2012;41(7):720-37.

24. Laiho O, Lahde E, Pukkala T. Uneven- vs even-aged management in Finnish boreal forests. Forestry. 2011:84(5):547-56.

25. Peura M, Burgas D, Eyvindson K, Repo A, Mönkkönen M. Continuous cover forestry is a cost-efficient tool to increase multifunctionality of boreal production forests in Fennoscandia. Biol Conserv. 2018;217:104-12.

26. Nolet P, Kneeshaw D, Messier C, Béland M. Comparing the effects of evenand uneven-aged silviculture on ecological diversity and processes: a review. Ecol Evol. 2018;8(2):1217-26.

27. Kortesmaa T, Jokela A. E-yearbook of food and natural resource statistics for 2016: Statistical facts on agriculture, forestry, fisheries and hunting in Finland. Helsinki: National Resources Institute Finland; 2017

28. Haddaway NR, Kohl C, Rebelo da Silva N, Schiemann J, Spök A, Stewart $R$, et al. A framework for stakeholder engagement during systematic reviews and maps in environmental management. Environ Evid. 2017;6(1):11.

29. Livoreil B, Glanville J, Haddaway NR, Bayliss H, Bethel A, de Lachapelle FF, et al. Systematic searching for environmental evidence using multiple tools and sources. Environ Evid. 2017;6(1):23.

30. Frampton GK, Livoreil B, Petrokofsky G. Eligibility screening in evidence synthesis of environmental management topics. Environ Evid. 2017:6(1):27.

31. Kataja-aho S, Hannonen P, Liukkonen T, Rosten H, Koivula MJ, Koponen $\mathrm{S}$, et al. The arthropod community of boreal Norway spruce forests responds variably to stump harvesting. For Ecol Manage. 2016;371:75-83.

32. Chao A, Gotelli NJ, Hsieh TC, Sander EL, Ma KH, Colwell RK, et al. Rarefaction and extrapolation with Hill numbers: a framework for sampling and estimation in species diversity studies. Ecol Monogr. 2014;84(1):45-67. 